\title{
Robotic-assisted nephrectomy with level II IVC thrombectomy using Rummel Tourniquets
}

Christopher Pulford ${ }^{1}$, Kevin Keating 2, Matthew Rohloff ${ }^{2}$, David Peifer ${ }^{2}$, Richard Eames ${ }^{2}$, Jaschar Shakuri-Rad ${ }^{2}$, Thomas Maatman ${ }^{2}$

${ }^{1}$ Arizona College of Osteopathic Medicine, Midwestern University, Glendale, AZ, USA; ${ }^{2}$ Department of Urology, Metro Health, University of Michigan, Wyoming, MI, USA

\section{ABSTRACT}

Background: Inferior vena cava (IVC) invasion from renal cell carcinoma (RCC) occurs at a rate of 4-10\% (1). IVC thrombectomy (IVC-TE) can be an open procedure because of the need for handling of the IVC (2). The first reported series of robotic management of IVC-TE started in 2011 for the management of Level I - II thrombi with subsequent case reports in recent years (2-5).

Materials and Methods: The following is a patient in his 50's with no significant medical history. Magnetic resonance imaging and IR venogram were performed preoperatively. The tumor was clinical stage T3b with a $4.3 \mathrm{~cm}$ inferior vena cava thrombus. The patient underwent robotic assisted nephrectomy and IVC-TE. Rummel tourniquets were used for the contralateral kidney and the IVC. The tourniquets were created using vessel loops, a 24 French foley catheter and hem-o-lock clips.

Results: The patient tolerated the surgical procedure well with no intraoperative complications. Total surgical time was 274 min with 200 minutes of console time and 22 minutes of IVC occlusion. Total blood loss in the surgery was $850 c c$. The patient was discharged from the hospital on post-operative day 3 without any complications. The final pathology of the specimen was pT3b clear cell renal cell carcinoma Fuhrman grade 2 . The patient followed up post-operatively at both four months and six months without disease recurrence. The patient continues annual follow-up with no recurrence. Conclusions: Surgeon experience is a key factor in radical nephrectomy with thrombectomy as patients have a reported 50-65\% survival rate after IVC-TE (4).

\section{ABBREVIATIONS \\ IVC $=$ Inferior vena cava \\ $\mathrm{RCC}=$ renal cell carcinoma \\ IVC-TE = IVC thrombectomy \\ IR = interventional radiology}

\section{AUTHOR DISCLOSURE STATEMENT}

Authors have received and archived patient consent for video recording/publication in advance of video recording procedure. 


\section{SOURCE OF WORK}

All work is original from TM and Metro Health - University of Michigan.

\section{CONFLICT OF INTEREST}

None declared.

\section{REFERENCES}

1. Wang B, Li H, Huang Q, Liu K, Fan Y, Peng C, et al. Robotassisted Retrohepatic Inferior Vena Cava Thrombectomy: First or Second Porta Hepatis as an Important Boundary Landmark. Eur Urol. 2018; 74:512-20.

2. Abaza R. Initial series of robotic radical nephrectomy with vena caval tumor thrombectomy. Eur Urol. 2011; 59:652-6.

3. Chopra S, Simone G, Metcalfe C, de Castro Abreu AL, Nabhani J, Ferriero M, et al. Robot-assisted Level II-III Inferior Vena Cava Tumor Thrombectomy: Step-by-Step Technique and 1-Year Outcomes. Eur Urol. 2017; 72:267-74. Erratum in: Eur Urol. 2021; 80:e64.
4. Shao P, Li J, Qin C, Lv Q, Ju X, Li P, et al. Laparoscopic Radical Nephrectomy and Inferior Vena Cava Thrombectomy in the Treatment of Renal Cell Carcinoma. Eur Urol. 2015; 68:115-22.

5. Nelson RJ, Maurice MJ, Kaouk JH. Robotic Radical Left Nephrectomy With Inferior Vena Cava Level III Thrombectomy. Urology. 2017; 107:269.
Submitted for publication:

May 14, 2021

Accepted after revision:

May 20, 2021

Published as Ahead of Print:

September 10, 2021
Correspondence address:

Christopher Pulford, MD

Department of Surgery

Creighton University, Arizona Health

Education Alliance,

3100 N. Central Avenue,

Phoenix AZ 85012

Email: cpulford98@midwestern.edu

\section{ARTICLE INFO}

\section{Christopherh}

https://orcid.org/0000-0002-2068-7714

Available at: http://www.intbrazjurol.com.br/video-section/20210393_Pulford_et_al

Int Braz J Urol. 2022; 48 (Video \#01): 196-7 